\title{
APLICAÇÃO DO BALANCED SCORECARD: UM ESTUDO DE CASO EM UM ESCRITÓRIO DE CONTABILIDADE EM CASCAVEL - PR
}

\author{
Gessica Vigo Young Moura ${ }^{1}$ \\ Sabrina Menegoto Limberger ${ }^{2}$ \\ Bruno Hussein Dalla Líbera ${ }^{3}$
}

MOURA, G. V. Y.; LIMBERGER, S. M.; LÍBERA, B. H. D. Aplicação do balanced scorecard: um estudo de caso em um escritório de contabilidade em Cascavel - PR. Rev. Ciênc. Empres. UNIPAR, Umuarama, v. 19, n. 2, p. 225242, jul./dez. 2018.

RESUMO: Este trabalho tem como objetivo comprovar a importância e a eficiência da aplicação do Balanced Scorecard como ferramenta gerencial, a fim de aumentar a eficiência, a produtividade e melhorar a capacidade dos funcionários, em uma empresa de contabilidade em Cascavel-Paraná. A pesquisa foi realizada para mostrar a dificuldade que os escritórios de contabilidade enfrentam para atender a demanda de informações necessárias para as empresas no âmbito de gerar novas estratégias e como o Balanced Scorecard pode ajudar neste problema de gestão e organização. $\mathrm{O}$ estudo foi realizado com base em pesquisas bibliográficas e análise documental, caracterizada como qualitativa e descritiva, através de um estudo de caso. Apresenta-se no Balanced Scorecard a visão, a missão e as estratégias da empresa. Demonstra-se, mediante quadro, a Análise Swot com suas forças, fraquezas, oportunidades e ameaças. Com um conjunto de indicadores de desempenho desenvolvidos em quatro perspectivas: financeiro, de clientes, processos internos e aprendizagem e crescimento, faz-se a análise das mesmas, mediante a apresentação de quadros, sendo possível a aplicação de medidas concretas para que a empresa consiga alcançar seus objetivos. E ao final, por meio de um feedback, demonstra-se em que medida as mesmas foram corretamente aplicadas, se os objetivos foram alcançados e a visão foi realizada. PALAVRAS-CHAVE: Balanced Scorecard; Indicadores de desempenho; Gestão estratégica.

DOI: $10.25110 /$ receu.v19i2.6751

${ }^{1}$ Bacharel em Ciências Contábeis pela UNIPAR-Universidade Paranaense, unidade de Cascavel/PR. E-mail: gessica.vigo89@gmail.com

${ }^{2}$ Bacharel em Ciências Contábeis pela UNIPAR-Universidade Paranaense, unidade de Cascavel/PR. E-mail: sabrina.m.1@outlook.com

${ }^{3}$ Especialista em Gestão Tributária pela Univel, Especialista em Administração Financeira, Contábil e Controladoria pelo Ibrap. E-mail: brunohdl@hotmail.com 


\section{APPLICATION OF A BALANCED SCORECARD: A CASE STUDY IN AN ACCOUNTING FIRM IN CASCAVEL - PR}

ABSTRACT: This paper aims at proving the importance and efficiency of the Balanced Scorecard as a managerial tool to increase efficiency, productivity and enhance the capacity of employees in an accounting firm in the city of Cascavel, in the state of Paraná. The research was developed to show the difficulty accounting firms face to meet the demand for information required by companies to generate new strategies and how the Balanced Scorecard can help solve this managerial and organizational issue for companies. The study is based on a bibliographic research and on documentary analysis, with a qualitative and descriptive approach through a case study. The Balanced Scorecard presents the vision, mission and strategy of the company. A Swot Analysis is presented, listing the company's strengths, weaknesses, opportunities and threats. The analysis was carried out based on four performance indicators: financial, customer, internal processes, and learning and growth. Thus, solid measures could be applied for the company to achieve its objectives. Finally, through feedback, this study intends to demonstrate if the measures were correctly applied and if the objectives and vision could be achieved.

KEY WORDS: Balanced Scorecard; Performance indicators; Strategic management.

\section{APLICACIÓN DEL BALANCED SCORECARD: UN ESTUDIO DE CASO EN UNA OFICINA DE CONTABILIDAD EN CASCAVEL - PR}

RESUMEN: Este trabajo tiene como objetivo comprobar la importancia y la eficiencia de la aplicación del Balanced Scorecard como herramienta gerencial, a fin de aumentar la eficiencia, la productividad y mejorar la capacidad de los empleados, en una empresa de contabilidad en Cascavel-Paraná. La encuesta fue realizada para mostrar la dificultad que las oficinas de contabilidad enfrentan para atender la demanda de informaciones necesarias para las empresas en el marco de generar nuevas estrategias y cómo el Balanced Scorecard puede ayudar en este problema de gestión y organización. El estudio fue realizado con base en investigaciones bibliográficas y análisis documental, caracterizada como cualitativa y descriptiva, a través de un estudio de caso. Se presenta en el Balanced Scorecard la visión, la misión y las estrategias de la empresa. Se demuestra, mediante cuadro, el Análisis Swot con sus fuerzas, debilidades, oportunidades y amenazas. Con un conjunto de indicadores de desempeño desarrollados en cuatro perspectivas: financiero, de clientes, procesos internos y aprendizaje y crecimiento, se hace el análisis de las mismas, mediante la presentación de cuadros, 
siendo posible la aplicación de medidas concretas para que la empresa consiga alcanzar sus objetivos. Y al final, por medio de un feedback, se demuestra en qué medida las mismas se aplicaron correctamente, si los objetivos se alcanzaron y la visión fue realizada.

PALABRAS CLAVE: Balanced Scorecard; Indicadores de desempeño; Gestión estratégica.

\section{INTRODUÇÃO}

A contabilidade foi moldando-se à medida que as necessidades de cada época se tornavam diferentes. Para Lopes (2011), o profissional contábil que era conhecido como "guarda-livros" ou o "gerador de tributos", deixou essa expressão de lado e passou a ter uma função mais estratégica dentro das empresas. Dessa maneira, já não basta elaborar relatórios contábeis e financeiros, deve-se mostrar aos gestores como utilizar esses relatórios de forma que tomem decisões corretas e eficazes, a fim de alcançarem seus objetivos. Os profissionais dos escritórios de contabilidade devem manter-se atualizados diariamente, pois as regras governamentais estão sempre mudando. Também precisam ter uma equipe qualificada para atender todas as atividades e tarefas mensais, o que em algumas vezes, pode tornar-se um problema devido ao acúmulo de afazeres e a desqualificação profissional encontrada no mercado de trabalho. Assim, para aumentar a produtividade é necessário utilizar uma ferramenta de gestão e alinhar os objetivos às estratégias para um bom gerenciamento e crescimento da entidade.

Uma boa ferramenta gerencial deve envolver todos os integrantes da entidade, desde a alta administração até os colaboradores, fazendo com que esses entendam e participem do crescimento da empresa, treinando-os e mantendo-os motivados. Também deve-se manter uma periodicidade no acompanhamento dos processos do escritório, planejando e estabelecendo metas. Um exemplo de ferramenta de gestão é o Balanced Scorecard, que é suficientemente eficaz para um escritório contábil, devido aos requisitos já mencionados. Por meio dele é possível aplicar as metas e estratégias de forma prática em toda a organização, a fim de alcançar os objetivos de um planejamento estratégico.

O BSC é um sistema de gestão estratégica criado por Robert Kaplan, professor da Universidade de Harvard, e pelo consultor David Norton, em 1990. Segundo Kaplan e Norton (1997), por meio de um mapa de indicadores de desempenho o Balanced Scorecard traduz a visão e a missão da empresa, seguindo quatro perspectivas, que são: financeira, de cliente, dos processos internos e de aprendizagem e crescimento. Esses indicadores devem ser interligados, pois um depende do outro, podendo saber assim, quais impactos tem a decisão de uma área para outra. 
Diante das considerações apresentadas, o Balanced Scorecard pode ou não ajudar no processo de gestão e planejamento de um escritório de contabilidade? Para solucionar esse questionamento, nessa pesquisa será apresentado um estudo de caso em um escritório de contabilidade situado na cidade de Cascavel-Paraná.

Este trabalho tem por finalidade estudar a aplicação do Balanced Scorecard em um escritório de contabilidade situado na cidade de Cascavel-Paraná.

\section{REVISÃO BIBLIOGRÁFICA}

\subsection{Balanced Scorecard - BSC}

O BSC foi criado por Robert Kaplan, que era professor da Universidade de Harvard, e David Norton, que era consultor. Em 1990, os dois dirigiram um estudo de pesquisa para algumas empresas, buscando por novos métodos para medir o desempenho. O motivo desse estudo está ligado à razão de que existiam somente medidas financeiras, e essas medidas estavam se tornando ineficazes para as empresas que estavam surgindo, cada vez mais modernas, pois não ofereciam indicadores futuros.

O estudo foi motivado pela crença de que os métodos existentes para avaliação do desempenho empresarial, em geral apoiados nos indicadores contábeis e financeiros, estavam se tornando obsoletos. Os participantes do estudo acreditavam que depender de medidas de desempenho consolidadas, baseadas em dados financeiros, estava prejudicando a capacidade das empresas de criar valor econômico para o futuro. (KAPLAN; NORTON,1997, p.7).

Antes do BSC existia somente a perspectiva financeira, na qual eram analisados os dados no passado, como os lucros que foram obtidos e as vendas efetuadas. O BSC manteve a perspectiva financeira, mas trouxe outras três perspectivas, que são: a de clientes, dos processos internos, e de aprendizado e crescimento.

Segundo Kaplan e Norton (1997), grande parte das empresas avaliava seu desempenho somente com medidas financeiras. A estrutura do BSC manteve a medida financeira, mas como sendo consequência das demais perspectivas.

Crepaldi também tem uma visão sobre as medidas financeiras. Segundo Crepaldi (2011, p.331) "[...] Os modelos tradicionais de performance financeira serviram bem à era industrial, mas já não são apropriados para direcionar e avaliar habilidades e competências que as empresas da era do conhecimento devem dominar". 
Não tem como avaliar uma empresa somente com perspectivas financeiras, uma empresa não é feita só de lucro, é necessário saber como está o relacionamento da empresa com os clientes, saber se há qualidade nos produtos ou serviços oferecidos e se possui colaboradores capacitados.

O BSC traduz a visão e a missão da empresa, sendo assim uma importante ferramenta de gestão, trazendo para as empresas que o aplicam um maior domínio de suas estratégias, alcançando mais facilmente seus objetivos. De acordo com Crepaldi (2011), o BSC traduz a visão e a missão da empresa a partir de seus indicadores de desempenho, mas para essa ferramenta de gestão dar certo é necessária a participação de todos os colaboradores da empresa, entendendo aonde se quer chegar para se dedicarem, a fim de atingir os objetivos traçados. Segundo Kaplan e Norton (1997, p. 25): "O Balanced Scorecard traduz missão e estratégia em objetivos e medidas, organizados segundo quatro perspectivas diferentes: financeira, do cliente, dos processos internos e do aprendizado e crescimento. [...]".

Essas quatro perspectivas são definidas da seguinte forma:

A Perspectiva Financeira mede o retorno financeiro da empresa apresentando as consequências das ações tomadas. As medidas e objetivos financeiros devem servir como base para as outras perspectivas do BSC.

Os objetivos financeiros servem de foco para os objetivos e medidas das outras perspectivas do scorecard. Qualquer medida selecionada deve fazer parte de uma cadeia de relações de causa e efeito que culminam com a melhoria do desempenho financeiro. (KAPLAN; NORTON,1997, p.49).

A Perspectiva de Clientes permite que as empresas emparelhem suas medidas de resultado voltadas aos clientes, como satisfação, retenção, aquisição, lucratividade e fidelidade, com os segmentos específicos de clientes e mercado, facilitando a criação de propostas de valor específicas para os clientes do segmento-alvo.

Citam Kaplan e Norton (1997, p. 68): "Portanto, a perspectiva dos clientes scorecard traduz a missão e estratégia da empresa em objetivos específicos para segmentos focalizados de clientes e mercados que podem ser comunicados a toda a organização". Na Perspectiva dos processos internos os objetivos e medidas são voltados para atender os acionistas e os clientes-alvo. São os recursos da empresa, qualidade dos produtos, baixo custo e curto prazo.

Para Kaplan e Norton (1997), os processos internos do Balanced Scorecard resultam em processos novos, fazendo com que uma empresa atinja a excelência e alcance seus objetivos financeiros e de clientes. Os mesmos autores 
afirmam:

No Balanced Scorecard, os objetivos e medidas para a perspectiva dos processos internos derivam de estratégias explícitas voltadas para o atendimento às expectativas dos acionistas e clientes-alvo. Essa análise sequencial, de cima para baixo, costuma revelar processos de negócios inteiramente novos nos quais a empresa deverá buscar a excelência. (KAPLAN; NORTON,1997, p.99).

Na Perspectiva de aprendizado e crescimento coloca-se em questão o bem-estar, o crescimento e aperfeiçoamento dos funcionários da entidade para que suas mentes estejam capacitadas e incentivadas a mobilizar-se aos objetivos da organização. Já as demais perspectivas citadas anteriormente mostram o que uma empresa deve fazer para aumentar o seu potencial e melhorar o desempenho.

O objetivo de satisfação dos funcionários reconhece que o ânimo dos funcionários e a satisfação com o emprego são hoje aspectos considerados altamente importantes pela maioria das empresas. Funcionários satisfeitos são uma precondição para o aumento da produtividade, da capacidade de resposta, da qualidade e da melhoria do serviço aos clientes. [...] (KAPLAN; NORTON,1997, p.135).

Quando se utiliza as quatro perspectivas juntas, pode-se ter uma visão ampla da situação atual e futura do negócio. Todavia, isso depende da capacidade que as organizações têm em aprender e aplicar essas perspectivas.

\subsection{Relação de causa e efeito e análise SWOT}

Como mencionado anteriormente, a perspectiva financeira é o reflexo das demais perspectivas; ela é sempre a primeira a ser citada, mas na prática é a última, pois se trata do retorno financeiro. É necessário, primeiramente, ter profissionais qualificados, para que se tenha uma produção de qualidade, conquistando e fidelizando clientes para que assim adquiram os produtos, aumentando as vendas e, consequentemente o retorno. A figura 1 demonstra essa relação. 
Figura 1: Relação de causa e efeito

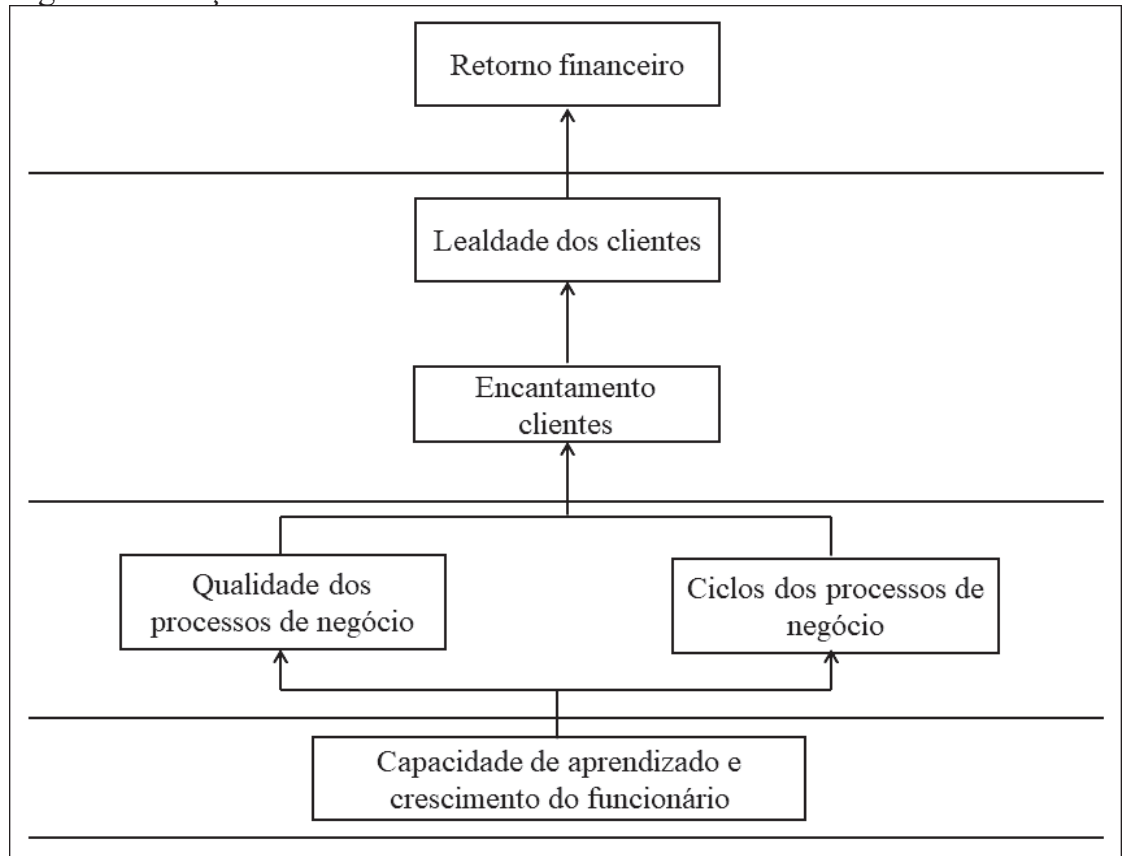

Fonte: Adaptado de Crepaldi (2011).

A partir de uma visão estratégica avalia o ambiente em que a empresa está inserida, de maneira interna e externa. Identifica as forças, as fraquezas, as oportunidades e as ameaças que estão relacionadas com a empresa. De acordo com Sertek, Guindani e Martins (2011), a sigla SWOT corresponde às palavras em inglês strenghts (pontos fortes), weaknesses (pontos fracos), opportunities (oportunidades), threats (ameaças).

Referente ao ambiente interno Sertek, Guindani e Martins (2011, p. 151) asseveram o que "[...] Pontos fortes/forças: São os aspectos que correspondem a vantagens internas da empresa em relação às concorrentes. Pontos fracos/ fraquezas: São os aspectos que correspondem a certas formas negativas da empresa que devem ser vistas". Já, referente ao ambiente externo Sertek, Guindani e Martins (2011, p.151) destacam que:

[...] Oportunidades: Referem-se aos aspectos positivos do ambiente que envolvem a empresa e que possuem potencial para lhe trazer vantagem competitiva. Ameaças: Referem-se aos aspectos negativos no ambiente que en- 
volvem a empresa e que possuem potencial para comprometer a vantagem competitiva que ela possui.

A análise SWOT faz com que os gestores ampliem a sua visão estratégica, referente a acontecimentos que não estão evidentes no momento, assim conhecendo melhor o seu negócio e o mercado em que a empresa está inserida. Ambiente interno: Se refere a uma visão global de toda a empresa, para saber o motivo para o sucesso ou para o fracasso atual e poder identificar a razão para o sucesso futuro. No ambiente interno observam-se as forças e as fraquezas, que são elementos que se pode administrar por meio da gestão. As forças são os benefícios da empresa e as fraquezas, são aquilo que a prejudicam.

\subsection{Missão, visão e valores}

A missão é a razão da empresa existir, são os benefícios que de algum modo a empresa traz para a sociedade. Segundo Niven (2005), a missão determina a finalidade central da entidade, tem a ver com a motivação dos funcionários, para que assim participem dos trabalhos da empresa. A missão tenta captar o que cada colaborador pode contribuir, o valor de cada um, para assim realizar a sua missão, fazendo algo de bom para a sociedade.

A visão é o objetivo da empresa, até aonde ela quer chegar, o que ela quer ser e como ela quer ser vista. Para Niven (2005, p. 103), "a afirmação de visão oferece um panorama geral daquilo que a organização, no fim das contas, pretende ser - o que pode levar 5, 10 ou 15 anos".

Já os valores, de acordo com Niven (2005) são princípios que dão a direção para uma organização, que são demonstrados a partir do comportamento dos colaboradores da empresa. Os valores de uma empresa demostram publicamente a maneira que ela espera que todos procedam.

\section{METODOLOGIA}

De acordo com Andrade (2007), pesquisar é utilizar métodos científicos para encontrar uma resposta para os problemas apresentados. Ou seja, pesquisar significa investigar, procurar respostas para algo que está sendo indagado. Nesta pesquisa foi utilizada a abordagem qualitativa para explanar o que é o Balanced Scorecard e quais são seus objetivos.

O estudo de caso investiga um fenômeno contemporâneo, seu contexto e suas características. Esse método foi escolhido pela necessidade de se verificar se o Balanced Scorecard pode influenciar na gestão de um escritório contábil, além de possibilitar que seja analisada sua aplicabilidade e, ao final, verificar seus resultados, bem como o retorno obtido por este estudo. 


\section{APRESENTAÇÃO E ANÁLISE DOS DADOS}

A colaboração da alta diretoria da empresa é muito importante para que o projeto possa ter bons resultados, tendo o consenso de disponibilizar as informações necessárias para elaborar o plano estratégico de forma eficiente. Antes de fazer a análise dos dados, foi preciso identificar a missão, a visão e os valores da empresa, que até então não eram definidos.

Verificou-se que a Missão da empresa é proporcionar aos clientes um atendimento diferenciado, fornecendo-lhes informações corretas e precisas para auxiliar em suas tomadas de decisão e, consequentemente, alcançar seus objetivos. Já a visão foi definida como: Ser reconhecido por Cascavel e região pela qualidade dos serviços prestados. Os valores identificados são: A ética, a transparência e o respeito.

Verificadas essas informações, foi realizada uma Análise Ambiental, para que pudessem ser identificadas as forças, as fraquezas, as oportunidades e as ameaças da mesma, a chamada Análise SWOT.

Quadro 1: Fatores internos de um escritório contábil de Cascavel-Paraná.

\begin{tabular}{|l|}
\hline \multicolumn{1}{|c|}{ FORÇAS } \\
\hline Vantagens oferecidas em relação ao \\
mercado:
\end{tabular}

\begin{tabular}{|l|}
\hline \multicolumn{1}{|c|}{ FRAQUEZAS } \\
\hline $\begin{array}{l}\text { Fatores que impedem resultados } \\
\text { potencialmente melhores: }\end{array}$ \\
\hline *Os funcionários estão em fase de \\
aprimoramento ou precisam atuali- \\
zar-se. \\
\hline *A demora das empresas para en- \\
tregarem os documentos para o es- \\
critório atrasa e diminui a qualidade \\
da contabilidade. \\
\hline *A falta de colaboração de alguns \\
clientes na entrega de documentos \\
necessários para apurações fiscais, \\
contábeis ou até mesmo do RH da \\
empresa fazem com que a qualida- \\
de do atendimento diminua e o tem- \\
po para o repasse das informações \\
gerenciais aumente.
\end{tabular}


*A área gerencial é a que mais se destaca e não é abordada pelos outros escritórios.

Fonte: Elaborado pelos autores, 2017.
*A falta de rotinas implementadas para que possíveis erros deixem de acontecer.

Quadro 2: Fatores externos de um escritório contábil de Cascavel-Paraná.

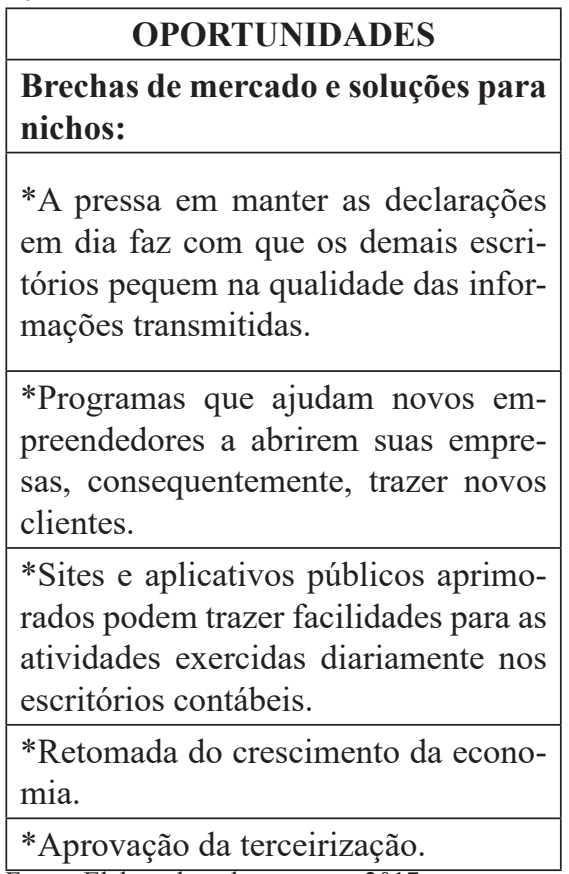

\begin{tabular}{|l|}
\hline \multicolumn{1}{|c|}{ AMEAÇAS } \\
\hline $\begin{array}{l}\text { Fatores externos que podem re- } \\
\text { duzir o potencial da empresa: }\end{array}$ \\
\hline *O baixo faturamento das empresas \\
em épocas de crise econômica faz \\
com que as empresas optem por fe- \\
char e, consequentemente, a perda \\
do cliente.
\end{tabular}
Fonte: Elaborado pelos autores, 2017.

Nessa primeira análise identificam-se as principais fraquezas da empresa e o que pode ser melhorado: A remessa de entrega de informações e declarações ao fisco faz com que o tempo se torne curto e a qualidade dos processos deixem a desejar. A demora na entrega dos documentos para a contabilidade também é um fator que influencia nessa qualidade.

Feita a Análise SWOT, parte-se para as perspectivas do Balanced Scorecard na seguinte ordem: Processos Internos, Aprendizagem e Crescimento, Clientes e Financeira. Essa ordem mostra a preocupação em transformar a empresa de dentro para fora, ou seja, sanando as dificuldades e erros internos, para que assim tragam resultados positivos às demais perspectivas.

Começando pela perspectiva financeira, que apesar de ser a primeira a 
ser apresentada é a última alcançada.

Quadro 3: Perspectiva financeira

\begin{tabular}{|c|c|c|c|}
\hline $\begin{array}{c}\text { Indicadores } \\
\text { Baturamento }\end{array}$ & $\begin{array}{c}\text { Objetivos } \\
\text { faturamentar o } \\
\text { bruto }\end{array}$ & $\begin{array}{c}\text { Mumento de } 30 \% \\
\text { até junho/2018 }\end{array}$ & $\begin{array}{c}\text { Captação de novos } \\
\text { clientes e oferta de } \\
\text { novos serviços. }\end{array}$ \\
\hline Lucro & $\begin{array}{c}\text { Aumentar o } \\
\text { lucro nominal }\end{array}$ & $\begin{array}{c}\text { Aumento } \\
\text { proporcional à } \\
\text { alavancagem } \\
\text { operacional, } \\
\text { durante o período. }\end{array}$ & $\begin{array}{c}\text { Iniciativa vinculada às } \\
\text { demais }\end{array}$ \\
\hline Capital & $\begin{array}{c}\text { Manter a } \\
\text { situação } \\
\text { Líquido } \\
\text { financeira } \\
\text { confortável } \\
\text { (liquidez) }\end{array}$ & $\begin{array}{c}\text { Não reduzir o CCL } \\
\text { até junho/2018 }\end{array}$ & $\begin{array}{c}\text { Aplicação de todas as } \\
\text { perspectivas anteriores } \\
\text { e manutenção de } \\
\text { aplicação financeira } \\
\text { fixa mensal pelo } \\
\text { escritório }\end{array}$ \\
\hline Inadimplência & $\begin{array}{c}\text { Reduzir a } \\
\text { inadimplência }\end{array}$ & $\begin{array}{c}\text { Reduzir em } 90 \% \\
\text { até o final de 2017, } \\
\text { para os clientes } \\
\text { ativos. }\end{array}$ & $\begin{array}{c}\text { Fazer cobranças mais } \\
\text { impositivas, todo final } \\
\text { de mês, com base nos } \\
\text { relatórios gerenciais. }\end{array}$ \\
\hline
\end{tabular}

Fonte: Elaborado pelos autores, 2017.

Apesar de o principal objetivo da empresa ser o aumento da rentabilidade e seu crescimento, para poder alcançá-lo é necessário que todas as iniciativas indicadas sejam aplicadas. Para que elas se concretizassem foi necessário o esforço de todos os integrantes da entidade, desde os funcionários até a alta administração. Por isso, a relação entre eles deve ser cordial e informativa, garantindo que os colaboradores estejam sempre integrados nos planos e metas da empresa.

Até então, o faturamento teve aumento de aproximadamente $7 \%$, devido à entrada de novas empresas, e o lucro manteve-se proporcional, devido à alavancagem operacional, o que demonstra que as metas financeiras criadas poderão ser cumpridas com totalidade no tempo estimado. A inadimplência encontra-se controlada, mas ainda existe um valor significativo de honorários em atraso até $08 / 2017$, os quais serão cobrados em momento oportuno. 
A próxima perspectiva é a de Clientes, a geração de capital da empresa, são eles que fazem com que o negócio continue existindo e progredindo. No quadro abaixo serão apresentadas as iniciativas direcionadas aos Clientes:

Quadro 4: Perspectiva de clientes

\begin{tabular}{|c|c|c|c|}
\hline Indicadores & Objetivos & Metas & Iniciativas \\
\hline \multirow{3}{*}{$\begin{array}{l}\text { Satisfação do } \\
\text { Cliente }\end{array}$} & $\begin{array}{l}\text { Aumentar a } \\
\text { satisfação do } \\
\text { cliente; }\end{array}$ & $\begin{array}{l}100 \% \text { dos } \\
\text { clientes até } \\
\text { dez/2018 }\end{array}$ & $\begin{array}{l}\text { Prestação de serviço } \\
\text { de qualidade e melhor } \\
\text { transmissão de dados } \\
\text { para tomada de decisões; }\end{array}$ \\
\hline & \multirow[t]{2}{*}{$\begin{array}{l}\text { Realizar } \\
\text { treinamentos } \\
\text { de todos os } \\
\text { departamentos a } \\
\text { todos os clientes }\end{array}$} & $\begin{array}{l}\text { Em } 100 \% \text { dos } \\
\text { clientes até o } \\
\text { final de } 2018\end{array}$ & $\begin{array}{l}\text { Treinamento inicial aos } \\
\text { novos clientes para a } \\
\text { habituação às rotinas } \\
\text { e procedimentos do } \\
\text { escritório; } \\
\text { Reuniões anuais para } \\
\text { atualização dos clientes } \\
\text { mais antigos; }\end{array}$ \\
\hline & & $\begin{array}{l}\text { Proximidade } \\
\text { com cliente }\end{array}$ & $\begin{array}{l}\text { Proximidade com o } \\
\text { cliente, realizando } \\
\text { visitas periódicas. }\end{array}$ \\
\hline \multirow[b]{2}{*}{$\begin{array}{l}\text { Quantidade } \\
\text { de Clientes }\end{array}$} & \multirow[b]{2}{*}{$\begin{array}{l}\text { Aumentar a } \\
\text { carteira de } \\
\text { clientes }\end{array}$} & $\begin{array}{l}\text { Aumentar em } \\
20 \text { clientes até } \\
\text { o final de } 2018 \\
\end{array}$ & \multirow{2}{*}{$\begin{array}{l}\text { Ofertas de serviços de } \\
\text { qualidade; } \\
\text { Manter e melhorar a } \\
\text { qualidade dos serviços; } \\
\text { Fazer com que a } \\
\text { qualidade dos serviços } \\
\text { satisfaça os clientes. } \\
\text { Indicação do escritório } \\
\text { às empresas novas } \\
\text { por meio dos próprios } \\
\text { clientes. }\end{array}$} \\
\hline & & $\begin{array}{l}\text { Não perder } \\
\text { nenhum cliente } \\
\text { até o final de } \\
2017\end{array}$ & \\
\hline
\end{tabular}

Fonte: Elaborado pelos autores, 2017.

Desde o início da aplicação do BSC até o mês de outubro não houve saída de nenhum cliente do escritório e verificou-se ainda um aumento de $10 \%$ no número de clientes.

Processos Internos: É a perspectiva que concentra a maioria dos problemas dentro da empresa, exibidos no seguinte quadro: 
Quadro 5: Perspectiva dos processos internos

\begin{tabular}{|c|c|c|c|}
\hline Indicadores & Objetivos & Metas & Iniciativas \\
\hline $\begin{array}{l}\text { Quantidade de } \\
\text { retrabalhos }\end{array}$ & $\begin{array}{l}\text { Reduzir a } \\
\text { quantidade de } \\
\text { retrabalho }\end{array}$ & $\begin{array}{l}\text { Reduzir o } \\
\text { retrabalho } \\
\text { em } 90 \% \text { até } \\
12 / 2017\end{array}$ & $\begin{array}{l}\text { Implantar rotinas } \\
\text { de fiscalização, } \\
\text { implementação de } \\
\text { protocolos e solução dos } \\
\text { problemas. }\end{array}$ \\
\hline $\begin{array}{l}\text { Tempo médio } \\
\text { de execução de } \\
\text { tarefas }\end{array}$ & $\begin{array}{l}\text { Redução do } \\
\text { tempo para } \\
\text { realizar as } \\
\text { tarefas }\end{array}$ & $\begin{array}{l}\text { Minimizar } \\
\text { o tempo em } \\
30 \% \text { para } \\
\text { cada atividade } \\
\text { até } 12 / 2017 \\
\end{array}$ & $\begin{array}{l}\text { Complementação da } \\
\text { parametrização do } \\
\text { sistema e organização } \\
\text { das tarefas em setores. }\end{array}$ \\
\hline $\begin{array}{l}\text { Índices de } \\
\text { empresas } \\
\text { controladas }\end{array}$ & $\begin{array}{l}\text { Controle de } \\
\text { vencimento } \\
\text { de alvarás, } \\
\text { licenças e } \\
\text { certificados; } \\
\text { Controle de } \\
\text { entrega de } \\
\text { documentos e } \\
\text { guias. }\end{array}$ & $\begin{array}{l}\text { Controlar em } \\
100 \% \text { todos os } \\
\text { vencimentos }\end{array}$ & $\begin{array}{l}\text { Digitalizar documentos } \\
\text { para facilidade do acesso } \\
\text { e agilidade das tarefas; } \\
\text { Elaboração de planilhas } \\
\text { de controle dos } \\
\text { vencimentos dos alvarás, } \\
\text { certificados e licenças; } \\
\text { Emissão de protocolos } \\
\text { de entrega de } \\
\text { documentos e guias; }\end{array}$ \\
\hline $\begin{array}{l}\text { Otimizar a } \\
\text { tecnologia dos } \\
\text { equipamentos }\end{array}$ & $\begin{array}{l}\text { Melhorar a } \\
\text { qualidade dos } \\
\text { equipamentos }\end{array}$ & $\begin{array}{l}\text { Até final } \\
06 / 2018\end{array}$ & $\begin{array}{l}\text { Compra de novos } \\
\text { computadores } \\
\text { e acessórios de } \\
\text { informática. }\end{array}$ \\
\hline $\begin{array}{l}\text { Ambiente } \\
\text { externo do } \\
\text { escritório }\end{array}$ & $\begin{array}{l}\text { Melhorar a } \\
\text { aparência e } \\
\text { estrutura do } \\
\text { escritório }\end{array}$ & $\begin{array}{l}\text { Até final de } \\
2018\end{array}$ & $\begin{array}{l}\text { Pintura, reforma e } \\
\text { fachada para que os } \\
\text { clientes se sintam mais } \\
\text { confortáveis ao adentrar } \\
\text { o ambiente. }\end{array}$ \\
\hline $\begin{array}{l}\text { Relação de RH } \\
\text { interno }\end{array}$ & $\begin{array}{l}\text { Trazer o RH } \\
\text { para dentro do } \\
\text { escritório }\end{array}$ & $\begin{array}{l}\text { Diminuir } \\
\text { os erros e } \\
\text { demora dos } \\
\text { processos em } \\
99 \%\end{array}$ & $\begin{array}{l}\text { Contratação de } \\
\text { funcionário para ficar } \\
\text { responsável e manter as } \\
\text { solicitações dos clientes } \\
\text { em dia. }\end{array}$ \\
\hline
\end{tabular}




\begin{tabular}{|l|l|l|l|}
\hline & & & $\begin{array}{l}\text { Divulgação com baixo } \\
\text { custo: Apresentação de } \\
\text { palestras e cursos. }\end{array}$ \\
$\begin{array}{l}\text { Relação de } \\
\text { Clientes que } \\
\text { utilizam as } \\
\text { demonstrações } \\
\text { elaboradas }\end{array}$ & $\begin{array}{l}\text { Aumentar } \\
\text { o interesse } \\
\text { das pessoas/ } \\
\text { clientes pela } \\
\text { contabilidade }\end{array}$ & $\begin{array}{l}\text { Pelo menos } \\
30 \% \text { dos } \\
\text { clientes até } \\
2018\end{array}$ & $\begin{array}{l}\text { Demonstrações } \\
\text { voltadas às informações } \\
\text { gerenciais, tais como } \\
\text { mark-up, alavancagem e } \\
\text { demais indicadores para } \\
\text { que os clientes possam } \\
\text { entender de maneira } \\
\text { efetiva. }\end{array}$ \\
\hline
\end{tabular}

Fonte: Elaborado pelos autores, 2017.

Nota-se a necessidade de organização e parametrização dos sistemas da empresa para que a prestação dos serviços se torne mais eficaz e ágil. Um dos fatores que estava causando dificuldades na relação cliente-escritório era a falta de comprovação de entrega de documentos. Após a implantação de protocolos de entrega foi eliminado o desgaste com as cobranças indevidas por documentos já enviados.

Até o final do ano passado o departamento pessoal era feito por terceiros e o módulo de recursos humanos do sistema utilizado pela contabilidade encontrava-se desparametrizado. Os processos eram feitos manualmente, como os ajustes dentro da folha mensal e em rescisões, os eventos e outros cadastros como de sindicatos ou as alíquotas do INSS estavam desatualizados ou não concluídos, aumentando a possibilidade de ocorrerem erros. O mesmo acontecia com os lançamentos e ajustes contábeis, bem como os parâmetros de auditoria que ainda não estavam cadastrados. Esses fatores acarretavam na demora da entrega dos documentos solicitados, gerando desconforto entre cliente e contabilidade, e também o mau aproveitamento das funcionalidades que o sistema oferece.

Após a contratação de uma pessoa para a área de recursos humanos, deixando o departamento internalizado e com o sistema parametrizado, os processos passaram a ficar mais rápidos e o percentual de erros diminuiu consideravelmente, proporcionando também um tempo maior para os demais integrantes do escritório se empenharem em suas atividades. $\mathrm{O}$ aumento do tempo, para dedicação às atividades de cada um, é um ideal da própria diretoria. O objetivo é que o tempo ocioso seja aproveitado para melhor verificação dos processos e estudo da área. O resultado obtido foi de empregados sem sobrecarga de atividades e interessados em prestar um atendimento com qualidade, mas não desacelerando a entrega dos serviços. Todas essas medidas influenciaram em uma maior organização do 
ambiente interno e melhoria dos serviços prestados.

No próximo quadro, evidenciam-se as necessidades encontradas na perspectiva de Aprendizagem e Crescimento da empresa:

Quadro 6: Perspectiva de aprendizagem e crescimento

\begin{tabular}{|c|l|l|l|}
\hline Indicadores & \multicolumn{1}{|c|}{ Objetivos } & \multicolumn{1}{|c|}{ Metas } & \multicolumn{1}{c|}{ Iniciativas } \\
\hline & $\begin{array}{l}\text { Satisfação } \\
\text { de todos os } \\
\text { colaboradores }\end{array}$ & Até final de 2018 & $\begin{array}{l}\text { Oportunizar } \\
\text { integração. }\end{array}$ \\
\cline { 2 - 4 } & $\begin{array}{l}\text { Especialização } \\
\text { dos funcionários }\end{array}$ & Até final de 2018 & $\begin{array}{l}\text { Incentivos } \\
\text { com cursos e } \\
\text { especialização. }\end{array}$ \\
\cline { 2 - 5 } $\begin{array}{l}\text { Satisfação dos } \\
\text { Colaboradores }\end{array}$ & $\begin{array}{l}\text { Desenvolvimento } \\
\text { de novos serviços } \\
\text { e competências }\end{array}$ & $\begin{array}{l}\text { Até final de 2017 } \\
\text { Pódulo RH } \\
\text { do programa } \\
\text { Cordilheira }\end{array}$ & $\begin{array}{l}\text { Divisão das } \\
\text { atividades em } \\
\text { setores. }\end{array}$ \\
\cline { 2 - 5 } & té final de 2017 & $\begin{array}{l}\text { Aplicação de } \\
\text { testes e cadastros } \\
\text { dos eventos } \\
\text { no sistema } \\
\text { cordilheira. }\end{array}$ \\
\hline & Gratificação & A partir de \\
$13 / 11 / 2017$ & $\begin{array}{l}\text { Conceder aos } \\
\text { colaboradores } \\
\text { gratificação de } \\
5 \% \text { para cada } \\
\text { cliente novo } \\
\text { que o escritório } \\
\text { adquirir. }\end{array}$ \\
\hline
\end{tabular}

Fonte: Elaborado pelos autores, 2017.

O objetivo dessa perspectiva é alcançar a satisfação de todos os colaboradores da empresa, para que se sintam satisfeitos em suas atividades e possam realizá-las com zelo e dedicação. O cuidado com a satisfação dos funcionários é uma poderosa arma para alcançar as metas da empresa, pois são eles os responsáveis em exercer as funções e atividades diárias que refletem a qualidade do atendimento da entidade.

Um funcionário insatisfeito e desanimado deixará de exercer suas atividades com exatidão ou destreza e poderá transferir essa falta de compromisso aos demais. Já um funcionário satisfeito e valorizado faz com que seu trabalho seja rentável e tenha vontade de participar do crescimento da empresa. Devido 
à empresa ser prestadora de serviços técnicos, deve investir no seu maior bem, que nada mais é que o capital intelectual de todos os colaboradores, afinal é ele que definirá o caminho que a entidade seguirá. Com colaboradores treinados e satisfeitos as perspectivas de sucesso serão maiores.

Em todas as perspectivas foram apresentadas as mais relevantes, aquelas que mais interferem para o alcance da visão e da missão da empresa.

\subsection{Feedback}

Após a inclusão do Balanced Scorecard e a aplicação das iniciativas dentro das quatro perspectivas, notam-se as melhorias no ambiente da empresa. Antes os setores desorganizados e desparametrizados desaceleravam os processos e a qualidade das atividades. A organização, a implementação de rotinas e novos modos de trabalho, a departamentalização dos setores de fiscal, de recursos humanos e contabilidade, fez com que as atividades ficassem mais rápidas e sem necessidade de retrabalho, já que apenas o responsável pelo setor está controlando.

O controle de vencimentos de certificados e alvarás das empresas e a geração de protocolos de entrega de documentos e guias preveniram as urgências e consequências negativas, como a não entrega de alguma guia deixando que passasse do prazo de pagamento, criadas pela falta de cuidado com esses relatórios que não eram fiscalizados.

A compra de novos equipamentos, como computadores e periféricos, auxiliou na agilidade dos processos, já que as atividades estão diretamente ligadas ao uso desses equipamentos e, consequentemente, na satisfação dos funcionários em terem o necessário para um bom desempenho em seu trabalho.

Houve mudanças no ambiente externo em relação ao paisagismo. No entanto, as reformas na estrutura externa do prédio, as placas e a pintura, estão sendo orçadas. O próprio empresário tem se encarregado de participar e realizar palestras na área contábil, permitindo que as pessoas tenham mais contato com essa área e adquiram maior interesse por uma boa contabilidade de suas empresas, fazendo também uma divulgação de seu trabalho.

A automação do sistema e o treinamento e aperfeiçoamento dos funcionários os tornou mais confiáveis e os deixou mais confortáveis, passando a trabalhar com mais tranquilidade e interesse. As perspectivas de Clientes e a Financeira, apesar de serem as mais visadas, são as que sofrem as alterações mais lentas, devido ao processo natural de desenvolvimento, mas, apesar disso, ainda alcançaram os resultados planejados, em razão da estagnação da economia. Houve ligeiro aumento na lista de clientes ativos. Foi possível notar a redução da inadimplência por meio da elaboração e controle de todos os contratos por sistema gerencial. 
Ainda, foi definida a contratação de um colaborador a fim de que todas as mudanças previstas no planejamento pudessem ser realizadas sem prejudicar o andamento dos trabalhos ordinários. Nesse sentido, a ociosidade foi utilizada estrategicamente, visando à melhoria no ambiente de trabalho e a disposição de tempo, necessário para a atualização dos colaboradores em suas áreas e parametrização de todas as rotinas, promovendo uma melhor qualidade de vida e um ambiente de trabalho tranquilo.

Foi implementada, a partir de 11/11/2017, a gratificação aos colaboradores pela produtividade e bônus em percentual do faturamento bruto, a fim de lhes possibilitar o desenvolvimento econômico e social, na proporção do crescimento do negócio. Em que pese o objetivo da empresa ser a geração de lucro, a cultura da organização atualmente está voltada ao desenvolvimento e valorização do capital humano, medida necessária para que qualquer empresa possa se desenvolver com consistência.

\section{CONSIDERAÇÕES FINAIS}

Com este estudo de caso pode se confirmar a importância e relevância da aplicabilidade do Balanced Scorecard em uma empresa como ferramenta de gestão e crescimento, conforme proposto no objetivo principal da pesquisa. Os dados apresentados comprovam uma visível melhoria da empresa em questão, o que faz notar as diferenças em uma empresa com gestão estratégica organizada.

O interesse e a participação dos administradores se torna um importante fator para que o projeto alcance bons resultados, visto que são eles os principais interessados na melhoria da empresa. A colaboração de todos, desde a alta administração aos colaboradores, fez com que os resultados aparecessem de forma rápida, efetiva ou ao menos provocando algum efeito positivo em curto prazo. Isso demonstrou que, para o Balanced Scorecard funcionar corretamente é essencial a conscientização quanto à necessidade dessas mudanças e a aceitação das mesmas por todos.

$\mathrm{O}$ fato da empresa analisada ser microempresa configura que o BSC funciona muito bem para todas as empresas, afinal a organização e gerenciamento são essenciais para qualquer negócio, proporcionando seu crescimento. Observa-se também maior facilidade na transmissão dos novos processos e aplicabilidades, pois a comunicação é repassada entre poucas pessoas, chegando rapidamente ao consenso e a aplicação das medidas adotadas, sem a necessidade de alterações burocráticas em diversos departamentos.

O sistema estratégico não possui formulação ou adoções de medidas engessadas, portanto, é cabível em qualquer área e porte empresarial, caracterizando-o como uma ferramenta versátil e eficaz por ser moldado de acordo com as 
perspectivas particulares da empresa e as necessidades do momento de mercado e da economia.

É importante que as empresas promovam mudanças face aos problemas organizacionais, para que, primeiramente, se preocupem em entender as causas dessas distorções, para posteriormente encontrar as medidas necessárias a fim de corrigi-las, pois é isso que o Balanced Scorecard faz. É devido a esses fatores que o BSC é reconhecido como uma metodologia de gestão eficaz.

\section{REFERÊNCIAS}

ANDRADE, M. M. Introdução à metodologia do trabalho científico. 5. ed. São Paulo: Atlas, 2007.

CREPALDI, S. A. Contabilidade Gerencial: teoria e prática. 5. ed. São Paulo: Atlas, 2011.

GIL, A. C. Como elaborar projetos de pesquisa. 5. ed. São Paulo: Atlas, 2010.

KAPLAN, R. S.; NORTON, D. P. A estratégia em ação: balanced scorecard. 2. ed. Rio de Janeiro: Campus, 1997.

LOPES, A. C. T. O guarda-livros e o contador gestor. Disponível em: $<$ http:// www.administradores.com.br/artigos/economia-e-financas/o-guarda-livros-e-ocontador-gestor/57957/>. Acesso em: 12 set. 2017.

NIVEN, P. R. Balanced scorecard passo a passo: elevando o desempenho e mantendo resultados. Rio de Janeiro: Qualitymark, 2005.

OLIVEIRA, E. Contabilidade informatizada: teoria e prática. São Paulo: Atlas, 1997.

SERTEK, P.; GUINDANI, R. A.; MARTINS, T. S. Administração e planejamento estratégico. 3. ed. Paraná: Ibpex, 2011.

YIN, R. K. Estudo de caso: planejamento e métodos. 5. ed. Porto Alegre: Bookman, 2015. 